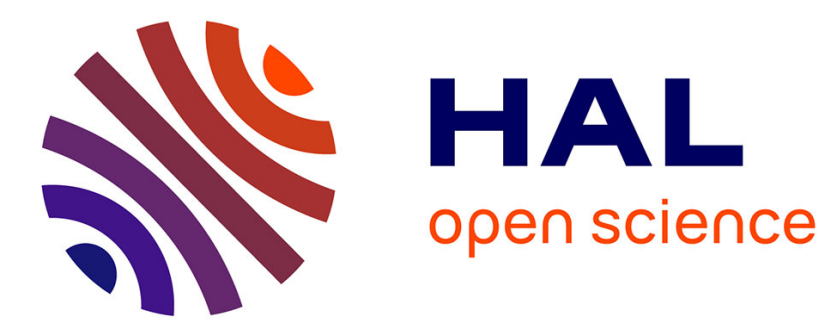

\title{
Continuous measurement of contact heat flux during minced meat grilling
}

\author{
Richard Rocca-Poliméni, Nuria Zárate Vilet, Stéphanie Roux, Jean-Luc
}

Bailleul, Bertrand Broyart

\section{To cite this version:}

Richard Rocca-Poliméni, Nuria Zárate Vilet, Stéphanie Roux, Jean-Luc Bailleul, Bertrand Broyart. Continuous measurement of contact heat flux during minced meat grilling. Journal of Food Engineering, 2019, 242, pp.163-171. 10.1016/j.jfoodeng.2018.08.032 . hal-02372822

\section{HAL Id: hal-02372822 \\ https://hal.science/hal-02372822}

Submitted on 9 Jun 2021

HAL is a multi-disciplinary open access archive for the deposit and dissemination of scientific research documents, whether they are published or not. The documents may come from teaching and research institutions in France or abroad, or from public or private research centers.
L'archive ouverte pluridisciplinaire HAL, est destinée au dépôt et à la diffusion de documents scientifiques de niveau recherche, publiés ou non, émanant des établissements d'enseignement et de recherche français ou étrangers, des laboratoires publics ou privés. 


\title{
Continuous measurement of contact heat flux during minced meat grilling
}

\author{
Richard Rocca-Poliméni ${ }^{\mathrm{a}}$, Nuria Zárate Vilet ${ }^{\mathrm{a}}$, Stéphanie Roux ${ }^{\mathrm{a}, *}$, \\ Jean-Luc Bailleul ${ }^{\mathrm{b}}$, Bertrand Broyart ${ }^{\mathrm{a}}$
}

a UMR Ingénierie Procédés Aliments, AgroParisTech, INRA, Université Paris-Saclay, 91300, Massy, France
${ }^{\mathrm{b}}$ UMR CNRS 6607, Laboratoire de Thermique et Energie de Nantes, Université de Nantes, 44300, Nantes, France

\begin{abstract}
Few studies concerning contact heating of food products were found in the literature despite the importance of this mode of heat transfer in many operations (grilling, pan-frying) and its drastic impact on product quality change during heating. An original heating device to measure continuously contact heat flux and heating surface temperature was therefore developed and applied to the contact heating of turkey meat with a heating surface at $128^{\circ} \mathrm{C}, 215^{\circ} \mathrm{C}$ and $255^{\circ} \mathrm{C}$. Based on the experimental results obtained, a simplified heat transfer model was developed and allowed the calculation of the parts of the total energy received by the product (i) used to raise its temperature (ii) used to evaporate water exuding from its lower surface during heating and (iii) lost by heat exchange with the surroundings. In the experimental conditions covered by our experiments, the part of energy used to evaporate water exuding from the product was found to vary between $55 \%$ and $67 \%$ of the total energy received. The precise evaluation of the kinetics of variation of the contact heat transfer coefficient (quantifying the quality of thermal contact between the lower surface of the meat sample and the heating plate) was also made possible. At $215^{\circ} \mathrm{C}$ and $255^{\circ} \mathrm{C}$, this coefficient ranged from 500 to $100 \mathrm{~W} \cdot \mathrm{m}^{-2} \cdot \mathrm{K}^{-1}$ between the start and the end of the cooking, these values being in the same order of magnitude as those measured in previous studies concerning single-faced grilling of meat.
\end{abstract}

\section{Introduction}

From industrial production to final preparation in the kitchens of consumers, food products undergo a large number of heat treatments. Different technologies may be used, including hot air or vapour heating, deep- or pan-frying, grilling, dielectric heating (microwave, high frequency), resistive (ohmic) heating or water cooking, etc. With the exceptions of dielectric and resistive heating, all these technologies are based on the implementation in a thermally-controlled environment of three elementary modes of external heat transfer: thermal convection, thermal radiation and contact heat transfer, the latter mode occurring when two solids at different temperatures are placed in contact.

Although many studies in the literature have been devoted to convection and radiation during the heating of food products (Erdoğdu, 2008; Rastogi, 2012), very few have focused on contact heat transfer. This seems paradoxical because contact heat transfer is the principal mode of heat transfer in many operations (single- or double-faced grilling, pan-frying) and is known to induce drastic quality changes in the zone of the product close to the heating surface, as studied for example by Kalogeropoulos et al. (2006), Sioen et al. (2006), Haak et al.
(2007) and Clerjon et al. (2012) with respect to pan-fried meat or fish and Boskou et al. (2006) for pan-fried potatoes.

The experimental and theoretical study of contact heat transfer on food products is rare because it is a complex matter. Firstly, the surface of a solid material will always present irregularities at the microscopic (roughness) or macroscopic scales (flatness anomalies, corrugations). As a result, the interface between these two solids in contact must always be envisioned as a series of contact spots interspersed with gaps, leading to an actual contact surface that is always smaller than the apparent contact surface (Madhusudana, 1996). As proposed by Incropera et al. (2007), the effect of the geometry of this complex interface upon heat transfer between the two solids in contact can be globally described by the use of a thermal contact resistance $R_{c t}$ defined according to equation (1):

$R_{c t}=\frac{T_{A}-T_{B}}{\dot{q}_{c t}}$

where $T_{A}-T_{B}$ is the temperature across the interface and $\dot{q}_{c t}$ is the resulting heat flux exchanged between the two solids.

When a food product is put in contact with a hot surface numerous

\footnotetext{
* Corresponding author.

E-mail addresses: richard.rocca@agroparistech.fr (R. Rocca-Poliméni), stephanie.roux@agroparistech.fr (S. Roux).
} 


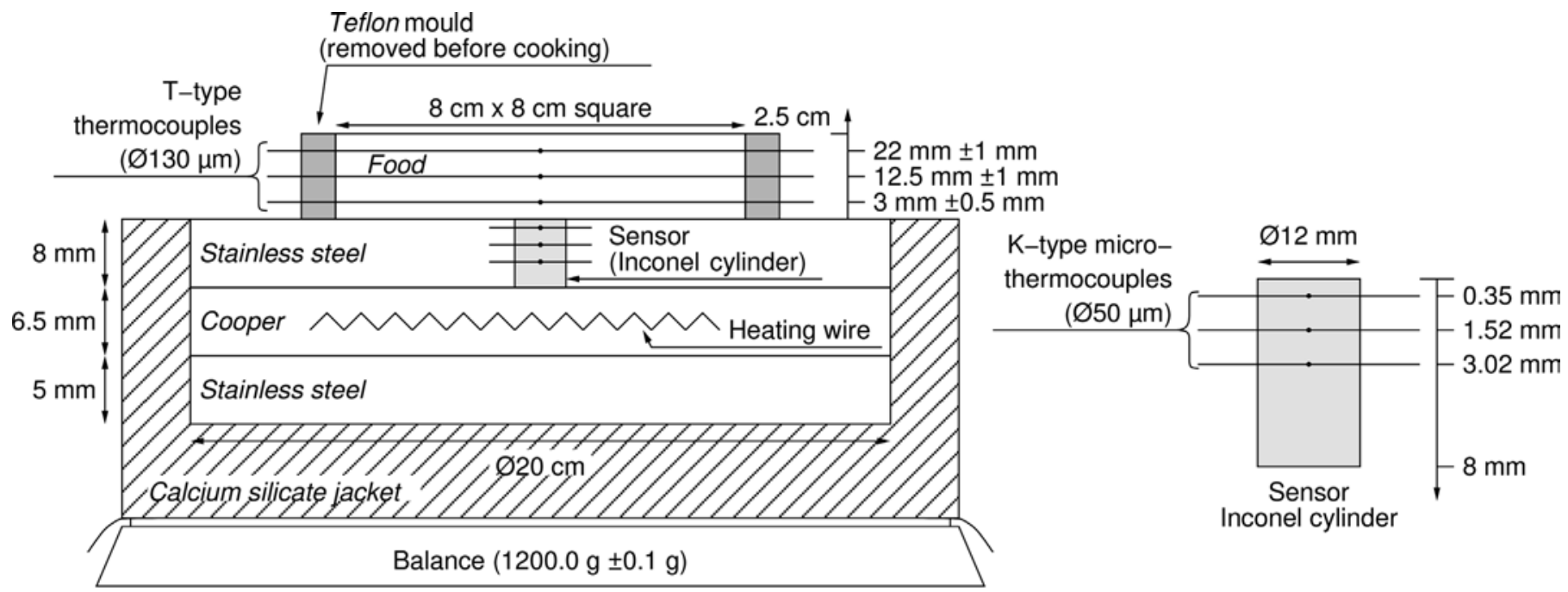

a) Schematic view

b) Sensor detail

Fig. 1. Experimental contact heating device.

thermally-induced physicochemical transformations occur in the heated product, leading to variations in the quality of the physical (and hence thermal) contact between the two surfaces. These interfering phenomena may occur continuously during heating or can happen very suddenly (boiling, detachment, etc.) They consist mainly in the formation of a crust on the lower surface of the product, followed by possible deformation or contraction of this surface and the potential release of cooking exudates from the heated product into the interstitial zone between the product and heating surface (Kondjoyan et al., 2014).

Concerning crust formation and deformation of the heated surface (as studied in meat by Portanguen et al., 2014, in bread by Vanin et al., 2013 and in pancakes by Sanz-Serrano et al., 2017), this phenomenon is likely to occur when the product surface is exposed to a high heat flux. This then leads to abrupt water evaporation at this exact location, the internal diffusion of moisture within the product being insufficient to compensate for this moisture loss. Once formed, this mechanically rigid crust causes the heated material to contract, thus tending to reduce the overall contact surface area between the product and heating surface. The crust also acts as a barrier layer to heat and mass transfer between the product and its surroundings.

Concerning the release of cooking exudates during heating or, by extension, the part played by an additional layer of oil between the product and heating surface, this allows the replacement of air as an interstitial medium between the two surfaces with a liquid medium which may improve the quality of the thermal contact between the two surfaces. However, study of the influence of cooking exudates during contact heating remains highly complex because most of these exudates vaporise when they come into contact with the heating surface, thus limiting overall heating of the product (Cernela et al., 2015).

Faced with this complexity, the most common method used to measure contact heat flux during the heating of solid food products consists in placing a surface heat flux sensor between the heating surface and the heated product (Houšová and Topinka, 1985; Pan and Singh, 2002; Pan et al., 2000; Wichchukit et al., 2001). This flux measurement, supplemented by two temperature measurements in the product and heating surface (as close as possible to the interface) enables the calculation of continuous variations in the contact heat transfer coefficient. This method provides an on-line and instantaneous measurement of thermal contact quality but (i) a small location error of the thermocouple in the product may lead to a major error regarding the surface temperature because very high temperature gradients are expected in the zone of the product close to the heating surface, (ii) product temperature is only measured at a local level that is not necessarily representative of the average lower product surface temperature, particularly for products presenting macroscopically noticeable surface irregularities, and (iii) positioning a surface heat flux sensor between the two materials will necessarily cause a local disturbance of heat and mass transfer phenomena at this location. More, it provokes (i) the addition of two supplementary resistances to heat transfer between the sensor and the product and between the sensor and the heating surface and (ii) the modification of mass transfer phenomena at the location of the sensor such as release and potential vaporisation of cooking exudates.

The aim of the present study was therefore to adapt, in order to measure precisely the contact heat transfer between a pan and a minced meat block, an original experimental device developed by Cernela et al. (2015) and precisely described in the following section. This device allowed the continuous measurement of the heating surface temperature whereas the heating device presented here allows also, after adaptation, the continuous and non-invasive measurement of the contact heat flux exchanged between the heating surface and heated product. The product chosen for this study was turkey meat since this product is commonly cooked by contact heating and exhibits complex phenomena during heating (crust formation, deformation, release of cooking exudates ...) The meat was minced before heating not to take into account the muscle anisotropy and to have a product whose structure is more repeatable for the heating test. A simplified heat and mass transfer model was also developed during this study in order to calculate continuous variations of the product's lower surface temperature and the contact heat transfer coefficient between the product's lower surface and the heating surface.

\section{Materials and methods}

\subsection{Contact heating device}

In order to perform contact heating experiments under controlled conditions, a contact heating device previously developed in our laboratory by Cernela et al. (2015) was modified in order to meet the objectives of the present study, which included continuous measurement of the contact heat flux exchanged between the heating surface and the heated product.

As shown in Fig. 1(a), the heating device was composed of three $20 \mathrm{~cm}$ diameter cylindrical metal discs placed inside a calcium silicate insulation jacket (Silicate L, Sored UPM, Messein, France). From bottom to top, the first disc was made of $5 \mathrm{~mm}$ thick stainless steel (Type 304), 
the second of $6.5 \mathrm{~mm}$ thick copper and the last of $8 \mathrm{~mm}$ thick stainless steel. The product to be heated was placed directly on the upper surface of this last disc, referred to as the "heating surface" in the remainder of this text. A heating wire of $3 \mathrm{~m}$ in length and $2 \mathrm{~mm}$ in diameter (Thermocoax, Suresnes, France) and delivering a power density up to $73 \mathrm{~kW} \cdot \mathrm{m}^{-2}$ was inserted into the bottom surface of the central copper disc. The high thermal conductivity of the copper disc enabled the delivery of uniform heat flux density at the upper surface of the third disk made of stainless steel.

To enable non-invasive measurements of the heating surface temperature and of the contact heat flux exchanged with the heated product, a cylindrical hole was drilled in the upper stainless steel disk to allow the insertion of a $8 \mathrm{~mm}$ high and $12 \mathrm{~mm}$ diameter cylinder made of Inconel 600 (Fig. 1(b)). The thermal properties of this material are very close to the ones of stainless steel so that the insertion of this Inconel cylinder does not perturb the heat transfer phenomena within the stainless steel disk. In fact, this Inconel cylinder comprised two halfcylinders allowing the precise positioning between them of three very thin ( $50 \mu \mathrm{m}$ diameter) K-type thermocouples at distances $z_{1}=0.35 \mathrm{~mm}$, $z_{2}=1.52 \mathrm{~mm}$ and $z_{3}=3.02 \mathrm{~mm}$ from the upper surface of this element (Kayme, Guyancourt, France). Contrary to the heating device developed by Cernela et al. (2015) which only used the temperature measured at $0.35 \mathrm{~mm}$ from the heating surface and assumed it to be equal to the heating surface temperature, the heating device developed in this study used the three temperature measurements to calculate the heating surface temperature and the contact heat flux according to a numerical procedure described in paragraph 2.2.

For the reasons explained below, particular care was taken to ensure that these temperatures were measured very precisely. To achieve this and to decrease the uncertainties on temperature measurements due the relative quality of integrated reference junction compensation provided by data acquisition manufacturers, the voltage provided by the thermocouples were directly measured using a 34970A data acquisition device equipped with a 34901A card (Agilent, Loveland, Colorado, USA). The cold junctions of the thermocouples were grouped in the same thermally insulated box and the reference junction temperature was measured in this box by two Pt-100 probes. Then, reference junction voltage were added and classic correlations were used to determined temperatures. The data acquisition system was then entirely calibrated to obtain an uncertainty for temperature measurements of less than $\pm 0.01^{\circ} \mathrm{C}$.

\subsection{Calculation of the heating surface temperature and contact heat flux}

The extent of heat exchange between the heating surface and the food product during contact heating affects undoubtedly the temperature gradients in the upper $8 \mathrm{~mm}$ thick stainless steel composing the heating device. Using the three temperature measurements realised in the Inconel cylinder and assuming one-dimensional heat conduction in it, the evaluation of heating surface temperature $T_{H S}(t)$ and contact heat flux density $\dot{q}_{c t}$ was performed by solving the inverse heat transfer problem defined as follows:

$\left\{\begin{array}{cccc}\frac{\partial T_{i c}}{\partial t}=\frac{k_{i c}}{\rho_{i c} \cdot C p_{i c}} \cdot \frac{\partial^{2} T_{i c}}{\partial z^{2}} & \text { for } t>0 \text { and } & z_{0}<z<z_{3} \\ -k_{i c} \cdot \frac{\partial T_{i c}}{\partial z}=\dot{q}_{c t}(t) & \text { for } t>0 \text { and } & z=z_{0} \\ T_{i c}=T_{3}(t) & \text { for } t>0 & \text { and } & z=z_{3} \\ T_{i c}=T_{0} & \text { for } t=0 & \text { and } & z_{0} \leq z \leq z_{3}\end{array}\right.$

where $T_{i c}$ is the temperature inside the Inconel cylinder calculated between $z_{0}=0 \mathrm{~mm}$ and $z_{3}=3.02 \mathrm{~mm}$. The thermophysical properties of Inconel 600 were assumed to be perfectly known and constant $\left(k_{i c}=16 \mathrm{~W} \cdot \mathrm{m}^{-1} \cdot \mathrm{K}^{-1}, \rho_{i c}=8470 \mathrm{~kg} \cdot \mathrm{m}^{-3}, C p_{i c}=470 \mathrm{~J} \cdot \mathrm{kg}^{-1} \cdot \mathrm{K}^{-1}\right)$. In our case, the temperature $T_{3}(t)$ measured experimentally in $z=z_{3}$ was used as one of the two boundary conditions of the problem and only the boundary heat flux $\dot{q}_{c t}$ in $z=z_{0}$ remained unknown.
Beck's sequential function specification method was chosen to solve this inverse heat transfer problem (Özişik and Orlande, 2000). It was implemented using Matlab R2015a (The MathWorks, Natick, Massachussetts, USA). The principle of this method is to determine the function $\dot{q}_{c t}(t)$ which minimises the differences between the experimental and calculated values of $T_{1}$ and $T_{2}$ evaluated respectively at distances $z_{1}$ and $z_{2}$ from the origin of the domain. The determined value of $\dot{q}_{c t}(t)$ is then used to deduce the value of the temperature of the heating surface at $z=z_{0}$ denoted in our study by $T_{H S}(t)$. It is important to note that the success of this method is conditional upon exact determination of the position of the thermocouples in the Inconel cylinder and on a very high accuracy of the measurements of $T_{1}, T_{2}$ and $T_{3}$. Particular attention was paid to these two points when designing our laboratory contact heating device.

\subsection{Preparation of food samples}

Turkey fillets $(\approx 700 \mathrm{~g}$ each) were purchased from a local supermarket (Volaille Française, Cora, Massy, France). To homogenise the products in terms of their structure, composition and geometry, the fillets are minced using a blender (RobotCoupe Blixer 4V.V, France) at a speed of $2000 \mathrm{rpm}$ for $1 \mathrm{~min} .180 \mathrm{~g}$ of the resulting mince was frozen at $-20^{\circ} \mathrm{C}$ and then packaged individually. It was then thawed over $24 \mathrm{~h}$ at $4^{\circ} \mathrm{C}$ and placed in an 8-cm square Teflon mould with a removable base. Slight compression was applied to obtain a meat block that was $2.5 \mathrm{~cm}$ thick, referred to as the "meat sample" in the remainder of this text.

\subsection{Measurement of mass loss and temperature rise affecting the meat sample}

Mass variations in the meat sample during heating were evaluated every minute by weighing the entire contact heating device using a SG8001 precision balance (Mettler Toledo, Viroflay, France) with a measurement uncertainty of $\pm 0.01 \mathrm{~g}$. For further calculations, the mass loss of the meat sample was assumed to be equal to its moisture loss. The initial moisture content of the minced meat was determined by weighing a sample of meat before and after complete desiccation for $24 \mathrm{~h}$ in a ventilated oven at $105^{\circ} \mathrm{C}$.

To measure the temperature rise of the meat sample during heating, specific T-type thermocouples were designed by welding $130 \mu \mathrm{m}$-diameter copper and constantan wires together (respectively TCFCP-00550FT and TFCC-005-50, Omega Engineering, Stamford, Connecticut, USA). These thermocouples were then inserted into the centre of the sample using a very thin glass tube and then spread horizontally within it through three pairs of holes bored at defined positions in the sides of the Teflon mould, located respectively at $3 \mathrm{~mm}, 12 \mathrm{~mm}$ and $22 \mathrm{~mm}$ from its base as shown in Fig. 1. The walls of the mould are then removed before starting the heating test.

After heating, the blocks of cooked minced meat were cut close to the thermocouples in order to check their position. Despite the precautions taken, it appeared that during either the preparation or heating of the meat sample, the thermocouples had shifted slightly from their initial positions. It was therefore decided to define three zones within the meat sample $(2.5-3.5 \mathrm{~mm}, 11.5-13.5 \mathrm{~mm}$ and $21-23 \mathrm{~mm}$ from its lower surface) and to assign each local temperature measurement to one of these three zones. For the same reasons, the measurements obtained by thermocouples positioned outside these three zones after heating were removed from our experimental dataset.

\subsection{Protocol for the contact heating test}

When using the laboratory contact heating device, the heating surface temperature was regulated using a PI controller whose parameters had previously been adjusted.

Before the test, the heating device was preheated and the temperature of the heating surface maintained at a given set-point 
temperature for at least $15 \mathrm{~min}$ before the start of the test. Three setpoint temperatures for the heating surface were chosen for our tests: $128{ }^{\circ} \mathrm{C}, 215{ }^{\circ} \mathrm{C}$ and $255^{\circ} \mathrm{C}$. The lower $\left(128{ }^{\circ} \mathrm{C}\right)$ and upper $\left(255^{\circ} \mathrm{C}\right)$ setpoint temperature values were chosen in light of the operating limits of the PI controller installed on the heating device. The intermediate (215 ${ }^{\circ} \mathrm{C}$ ) set-point temperature value was chosen because it had been found to be representative of the operating conditions to which food products are exposed during culinary applications such as pan-frying (Cernela et al., 2014). After preheating of the experimental device, the food product initially at ambient temperature was then placed on the surface for a test lasting $800 \mathrm{~s}$. To check the repeatability of the protocol, the heating tests at $215{ }^{\circ} \mathrm{C}$ were conducted a sufficient number of times to enable at least 6 kinetics of temperature rise to be available for each of the three zones of the product (as defined in paragraph 2.4). For the tests at $128^{\circ} \mathrm{C}$ and $255^{\circ} \mathrm{C}$, the experiments were performed in duplicate.

\section{Model development}

\subsection{Specific objectives of the model}

A simplified heat and mass transfer model was developed to predict local temperature rise and moisture loss kinetics inside the meat sample. This model therefore needed to be considered as a numerical tool that would enhance the scope of the experimental measurements obtained. Its particular aim was to evaluate certain physical variables of interest in order to characterise contact heating which were almost impossible to measure directly because of their location between the two media in contact.

\subsection{Governing equations, initial and boundary conditions}

To meet the objectives of the model detailed above, transport phenomena within the product were described using an approach as simple and robust as possible. The following assumptions were then made before developing the model:

(1) the meat sample was considered as a continuous medium of parallelepiped shape with constant thermophysical properties during heating. In fact, even if they could change according to water content (Abraham and Sparrow, 2007), the water content changes only in the crust and the crust size was too small to induce any significant modification of the conductive transfer in the meat product,

(2) the sum of all the phenomena responsible for heat transport within the meat sample was assumed to obey Fourier's law,

(3) overall moisture loss from the product was assumed to be due solely to the vaporisation of water exuding from its lower surface, the vaporisation of water from the other surfaces being considered as a negligible quantity,

(4) except at the product's lower surface where vaporisation of water occurred, moisture transport within the meat sample during heating was assumed not to affect temperature distribution within the sample during heating.

Based on these assumptions, the transient heat conduction equation was written in three dimensions to describe heat transfer phenomena within the meat sample during contact heating. The energy conservation equation thus took the form of equation (3).

$\rho \cdot C p \cdot \frac{\partial T}{\partial t}=k \cdot \nabla^{2} T$

The initial temperature in the meat sample was considered to be uniform so $T=T_{0}$ was fixed at $20{ }^{\circ} \mathrm{C}$. For the boundary condition written at the product's lower surface, the heat flux transported by conduction within the meat sample was taken to be equal to the heat flux density from the heating surface $\dot{q}_{c t}$ (counted as a positive value) reduced by the power associated with the assumed instantaneous vaporisation of liquid water exuding continuously from the meat sample, as shown by equation (4).

$-k \cdot \vec{\nabla} T \cdot \vec{n}=\dot{q}_{c t}+\frac{L_{v}}{S} \cdot \frac{d m}{d t}$

where $L_{v}=2.257 \times 10^{6} \mathrm{~J} \cdot \mathrm{kg}^{-1}$ is the latent heat of water vaporisation, $S=64 \mathrm{~cm}^{2}$ the contact surface and $\frac{d m}{d t}$ the instantaneous moisture loss rate calculated by a first order forward difference formula applied to discrete measurements of meat sample mass loss during heating. $\dot{q}_{c t}(t)$ was measured experimentally.

For the other surfaces of the parallelepiped meat sample, we used a global heat transfer coefficient $h$ (including radiative effects) to describe heat exchange with the surroundings at temperature $T_{\infty}=20^{\circ} \mathrm{C}$ :

$-k \cdot \nabla T \cdot \vec{n}=h \cdot\left(T-T_{\infty}\right)$

As a first approximation and noting that this variable had not a strong influence on the studied phenomenon, the value of the global heat transfer coefficient was fixed at $10 \mathrm{~W} \cdot \mathrm{m}^{-2} \cdot \mathrm{K}^{-1}$. This global heat transfer coefficient includes heat exchange between the surface of the product and the surroundings of the heating device (air in the room, walls of the room) by natural convection and thermal radiation. The value of $10 \mathrm{~W} \cdot \mathrm{m}^{-2} \cdot \mathrm{K}^{-1}$ has been calculated with a surface temperature equal to $\approx 50^{\circ} \mathrm{C}$ by the correlation provided by Incropera et al. (2007) and assuming that this temperature is of the same order of magnitude as the one reached by the upper surface of the product at the end of the heating test.

The system of partial differential equations constituted by equation (3) to equation (5) was solved using COMSOL Multiphysics v. 5.0 software (COMSOL AN, Stockholm, Sweden) in a quarter 3D-geometry piece of meat considering two planes of symmetry within the parallelepiped. The modelled domain was meshed into 63021 free tetrahedral elements. Model was solved by finite element method using backwards differentiation formula method. The absolute tolerance criteria on temperature was $0.001{ }^{\circ} \mathrm{C}$.

\subsection{Material properties and model parameters}

In equation (3), the density of the meat sample $\rho$ was measured by weighing a fixed volume of minced meat and a value of $1125 \mathrm{~kg} \cdot \mathrm{m}^{-3}$ was found for this property. Values for meat sample thermal conductivity $k$ and heat capacity $C p$ were identified by comparing the calculated and experimentally measured temperatures within the meat sample during heating. To achieve this, the sum of squared errors between the median temperature values measured in the three zones of the meat sample (see paragraph 2.4) and the average temperature calculated by the model in the same three zones was calculated and minimised using the Nelder-Mead Simplex algorithm already programmed in the Matlab environment.

\subsection{Further use of the results calculated by the model}

As already discussed, this model was developed to obtain a better insight into the heat transfer phenomena that occur between the product's lower surface and the heating surface. To achieve this, two types of calculations were performed.

In a first step, the results of the model were used to obtain an overall heat balance on the meat sample during contact heating. The aim was to make a clear distinction between (i) the total energy received by the product $E_{t o t}$, (ii) the energy consumed to raise its temperature, or so called sensible energy $E_{\text {sens }}$, (iii) the energy consumed by the vaporisation of water exuding from the product during heating $E_{\text {evap }}$ and (iv) the energy lost by heat exchange with the surroundings $E_{\text {loss. }}$. These calculations were performed according to the following procedure. First, $E_{\text {tot }}$ was calculated using the experimental contact heat flux values $\dot{q}_{c t}$ according to equation (6). 
$E_{t o t}(t)=S \cdot \int_{0}^{t} \dot{q}_{c t}(t) d t$

Then, $E_{\text {evap }}$ was calculated from the measurements of product mass variations using equation (7).

$E_{\text {evap }}(t)=-\Delta m(t) \cdot L_{v}$

where $\Delta m(t)$ is the total mass lost by the product since the start of the heating test. Finally, the surface temperature of the product $T_{F S}$ calculated by the model was used to calculate $E_{\text {loss }}$ according to equation (8).

$E_{\text {loss }}(t)=\int_{S^{\prime}} \int_{t} h \cdot\left(T_{F S}-T_{\infty}\right) d S^{\prime} d t$

where $S^{\prime}$ is the peripheral surface of the meat sample except for the its lower surface. Finally, $E_{\text {sens }}$ was calculated from the difference according to equation (9).

$E_{\text {sens }}(t)=E_{\text {tot }}(t)-E_{\text {evap }}(t)-E_{\text {loss }}(t)$

In a second step, the results of the model were used to determine variations in the contact heat transfer coefficient $h_{c t}$ using equation (10) (Incropera et al., 2007).

$h_{c t}(t)=\frac{\dot{q}_{c t}(t)}{T_{H S}(t)-T_{F S}(t)}$

where $T_{H S}$ is the temperature of the heating surface and $T_{F S}$ the temperature of the product's lower surface.

\section{Results and discussion}

\subsection{Evolution of temperature within the meat sample}

The kinetics of the rise in temperature in the three zones of the meat sample are shown in Fig. 2 for the tests performed at a set-point temperature for the heating surface of $215{ }^{\circ} \mathrm{C}$. Each curve on this graph represented a temperature measurement at a given location during a heating test.

The temperature profiles measured in the first zone of the product $(2.5 \mathrm{~mm}-3.5 \mathrm{~mm})$ displayed greater variability than those recorded in other zones. This was attributed to the high temperature gradients in the meat sample at this location. Therefore, a slight change to the vertical position of the thermocouple had a great impact on the temperature value measured. At all times in the first zone of the product, the curve for the rise in temperature exhibited a relatively long plateau at $100{ }^{\circ} \mathrm{C}$ (or a little bit lower than $100{ }^{\circ} \mathrm{C}$ due to the position of the

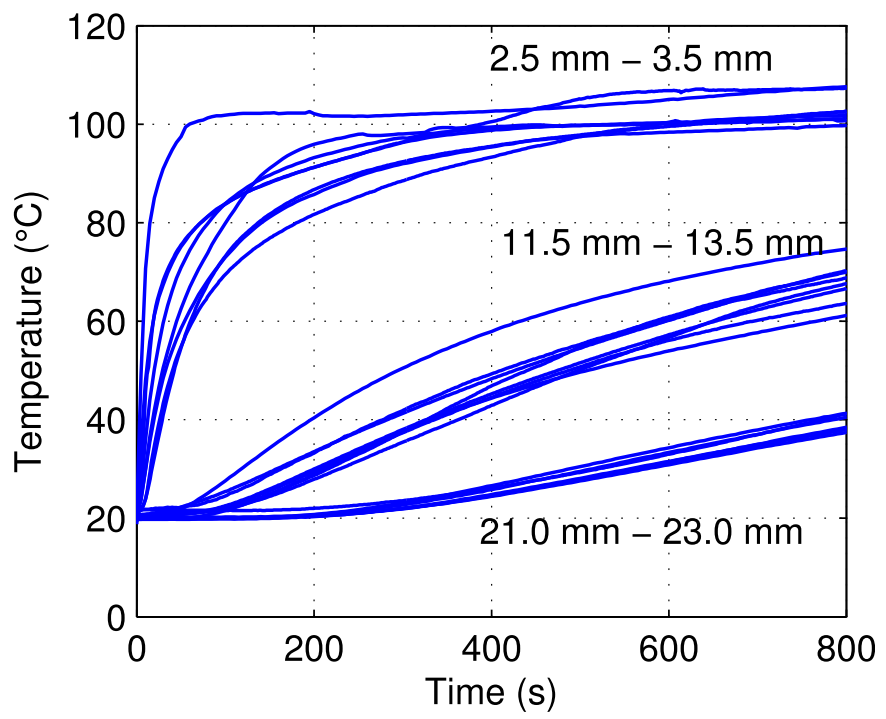

Fig. 2. Temperature profiles at three locations during cooking at $215^{\circ} \mathrm{C}$. thermocouples assumed just above the crust) before a rapid upturn when the crust size became high than $2.5 \mathrm{~mm}$. This value of $100{ }^{\circ} \mathrm{C}$ could be explained by visual observation of a continuous flow of liquid water exuding from the product's lower surface and vaporising rapidly when it came into contact with the heating surface. This phenomenon occurred during a significant part of the heating because of the high initial moisture content of the meat $(73.55 \% \pm 0.66$ wet basis) and due to the fact that moisture migration from the centre of the product to its lower surface was facilitated by the structure of the minced meat.

However, for some temperature profiles recorded close to the heating surface, an increase in temperature to above $100{ }^{\circ} \mathrm{C}$ was noted at the end of heating, indicative of drastic drying of the product's lower surface and the reheating of this dried zone. This was confirmed by the observation of a crust below the product after heating.

For temperatures measured elsewhere in the product, heating was judged to be moderate because the temperatures measured did not exceed $70{ }^{\circ} \mathrm{C}$ and $40{ }^{\circ} \mathrm{C}$ respectively in the second $(11.5-13.5 \mathrm{~mm})$ and third $(21-23 \mathrm{~mm})$ zones of the product. However, these temperatures correspond to a one side heat treatment and would enable to achieve a sufficient level of cooking at each point after turning the product, as classically done in pan-cooking. This result also confirmed the expected thermal heterogeneity induced by all the contact heating experiments involving materials with low thermal conductivity.

\subsection{Mass loss from meat sample}

Fig. 3 shows the mass loss (counted as positive) from the meat sample during heating. The variability between the different tests remained small. The higher variability observed at $128{ }^{\circ} \mathrm{C}$ could be representative of the operating limits of the heating device. Indeed, its non-negligible thermal inertia became a critical point to be managed by the regulation system when operating at a low set-point temperature. The results showed that the higher the set-point temperature, the greater was the rate of mass loss. It could also be noted that mass loss occurred at a significant rate from the very start of the heating test. This indicated that the product's lower surface, subjected to a very high heat flux, started to dry out almost instantaneously.

\subsection{Evolution of contact heat flux and heating surface temperature}

Fig. 4 (a) and (b) show the evolution of the contact heat flux $\dot{q}_{c t}(t)$ and the temperature of the heating surface $T_{H S}$ as a function of the

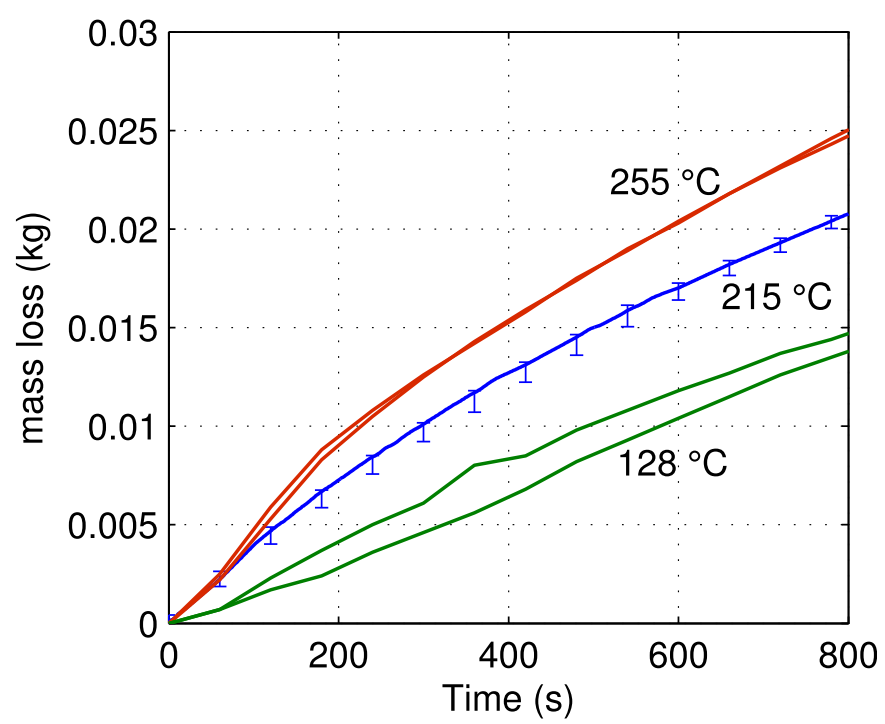

Fig. 3. Mass loss profiles at three different cooking temperatures (initial mass: $180 \mathrm{~g}$ ). Duplicates are presented for $128^{\circ} \mathrm{C}$ and $255^{\circ} \mathrm{C}$; the median (solid line), first and last quartiles (error bars) of five repetitions at $215^{\circ} \mathrm{C}$ are shown. 
a)

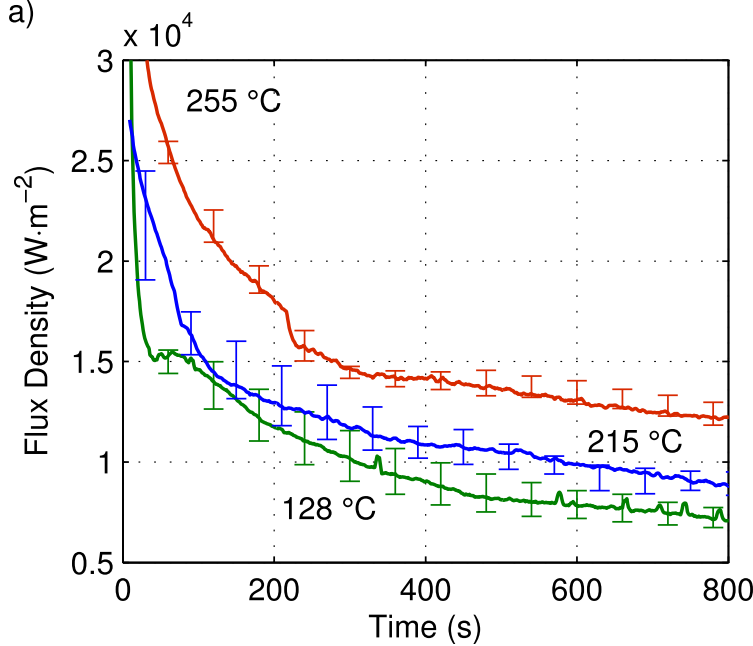

b)

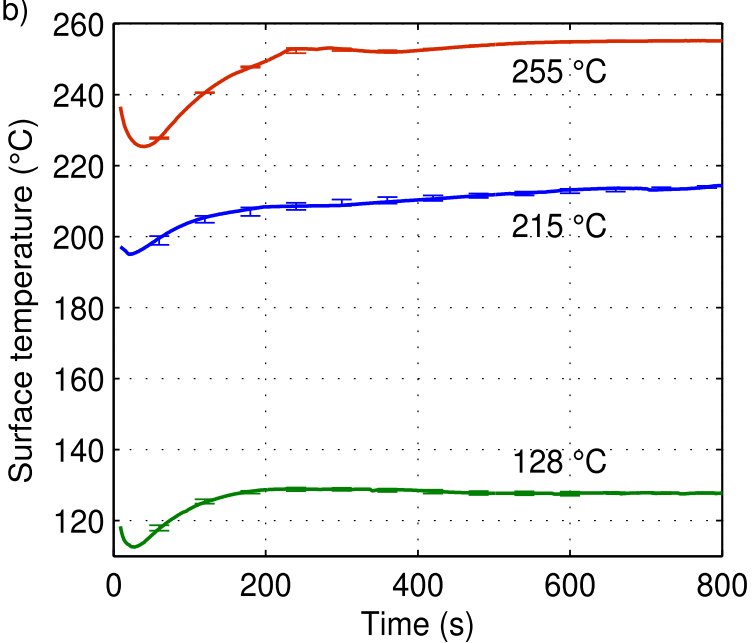

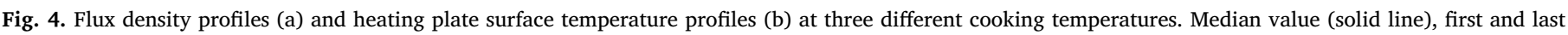
quartiles (error bars).

heating time $t$, respectively. For these two variables, the first points of the curves (for $t<10 \mathrm{~s}$ ) were not represented because the sampling period of the acquisition system used to measure the temperatures in the Inconel cylinder was $\approx 1 \mathrm{~s}$ and therefore insufficiently short to precisely estimate the variables of interest at the start of heating.

As shown in Fig. 4(a), when the product at ambient temperature was placed on the heating surface that was already at a high temperature, a massive and instantaneous heat transfer was noted between the two media. A peak in contact heat flux density was noted at the start of heating, with values of up to $30 \mathrm{~kW} \cdot \mathrm{m}^{-2}$. These contact heat flux values then fell markedly after this initial peak. Because the temperature of the heating surface did not fall by more than $15^{\circ} \mathrm{C}$ at the start of heating (see Fig. 4(b)), this abrupt decrease in the contact heat flux was attributed to the very rapid rise in the product's lower surface temperature. Such a result is typically observed when one surface of a solid food product (which can be viewed as an insulating material) is subjected to a high heat flux. During the heating tests, the massive heat flux received initially by the product's lower surface could not be transported instantaneously by conduction within the product due to its low thermal conductivity, so this limitation led to a very rapid rise in the temperature of the heated surface.

For longer heating times, the contact heat flux density values fell more moderately. During this period, the energy received by the product's lower surface was partly consumed by raising the temperature of the product and also vaporising the water exuding from the product. Calculations were performed to evaluate the respective share of these two phenomena. In general, the higher the set-point temperature of the heating surface, the higher were the contact heat flux density values at the end of heating: $750 \mathrm{~W} \cdot \mathrm{m}^{-2}, 850 \mathrm{~W} \cdot \mathrm{m}^{-2}$ and $1200 \mathrm{~W} \cdot \mathrm{m}^{-2}$ for setpoint temperatures of $128{ }^{\circ} \mathrm{C}, 215{ }^{\circ} \mathrm{C}$ and $255^{\circ} \mathrm{C}$, respectively.

Fig. 4(b) shows the variations in heating surface temperatures measured during the experiments. Although not represented, this temperature remained perfectly stable before the product was applied to this surface. After initial contact with the product, the temperature of the heating surface fell rapidly but moderately, a feature correlated positively with the set-point temperature and which ranged from $20{ }^{\circ} \mathrm{C}$ to $30{ }^{\circ} \mathrm{C}$. Theoretically, it has been shown that, if two semi-infinite bodies at initial and uniform temperatures $T_{1}$ and $T_{2}$ were brought in perfect thermal contact, the temperature at the contact surface for the two bodies $T_{m}$ and immediately after the contact could be calculated according:

$T_{m}=\frac{E_{1} \cdot T_{1}+E_{2} \cdot T_{2}}{E_{1}+E_{2}}$ where $E=\sqrt{k \cdot p \cdot C p}$ was the thermal effusivity evaluated here for each semi-infinite body (Taine and Petit, 1998). During our experiments and noting that the thermal effusivities for Inconel and meat were respectively 7981 and $1143 \mathrm{~W} \cdot \mathrm{kg}^{-1} \cdot \mathrm{m}^{-2} \cdot \mathrm{s}^{1 / 2}$, we calculated a theoretical contact temperature just after the contact equal to $226^{\circ} \mathrm{C}, 191{ }^{\circ} \mathrm{C}$ and $115{ }^{\circ} \mathrm{C}$ when the heating plate set-point temperature was respectively $255^{\circ} \mathrm{C}, 215^{\circ} \mathrm{C}$ and $128^{\circ} \mathrm{C}$. Even if the thermal contact between the meat and the heating plate could not be assumed perfect, these theoretical contact temperatures and the initial (just after the contact) temperature drop represented on Fig. 4(b) seemed in accordance.

After this initial decrease, the temperature of the heating surface tended to return to its initial value due to the action of the regulation system in the heating device. This system delivered heating power according to the difference between the actual and set-point temperatures; a greater difference thus required more power. This regulation system was deemed sufficiently efficient to meet the objectives of our study since the temperature of the heating surface was close to its setpoint value for up to $75 \%$ of the total heating time, the maximum deviation between the two values not exceeding $25{ }^{\circ} \mathrm{C}$.

\subsection{Comparison between experimental and calculated values}

As explained in paragraph 3.3, the thermal conductivity $k$ and heat capacity $C p$ values of the meat sample (assumed to be constant in our model) were identified by comparing the calculated and experimental temperature values inside the meat sample. The optimum values found were respectively $C p=2.7 \mathrm{~kJ} \cdot \mathrm{kg}^{-1} \cdot \mathrm{K}^{-1}$ and $k=0.43 \mathrm{~W} \cdot \mathrm{m}^{-1} \cdot \mathrm{K}^{-1}$, these being consistent with those found in the literature for poultry products (Marcotte et al., 2008).

Using these optimum values, the experimental and calculated temperature values in the meat sample were plotted in Fig. 5 for the tests at $215{ }^{\circ} \mathrm{C}$. A comparison between these data revealed the satisfactory agreement of experimental and calculated values. The method was therefore considered to be valid and ready for use, as described in section 3, (i) to obtain an overall heat balance for the entire meat sample during contact heating and (ii) to calculate the evolution of the product's lower surface temperature $T_{F S}$ and of the contact heat transfer coefficient $h_{c t}$.

\subsection{Overall heat balance of the meat sample during contact heating}

Fig. 6 shows the evolution of (i) the total energy received by the product $E_{\text {tot }}$, (ii) the energy used by the product to raise its internal energy, or so called sensible energy $E_{\text {sens }}$, (iii) the energy consumed by 


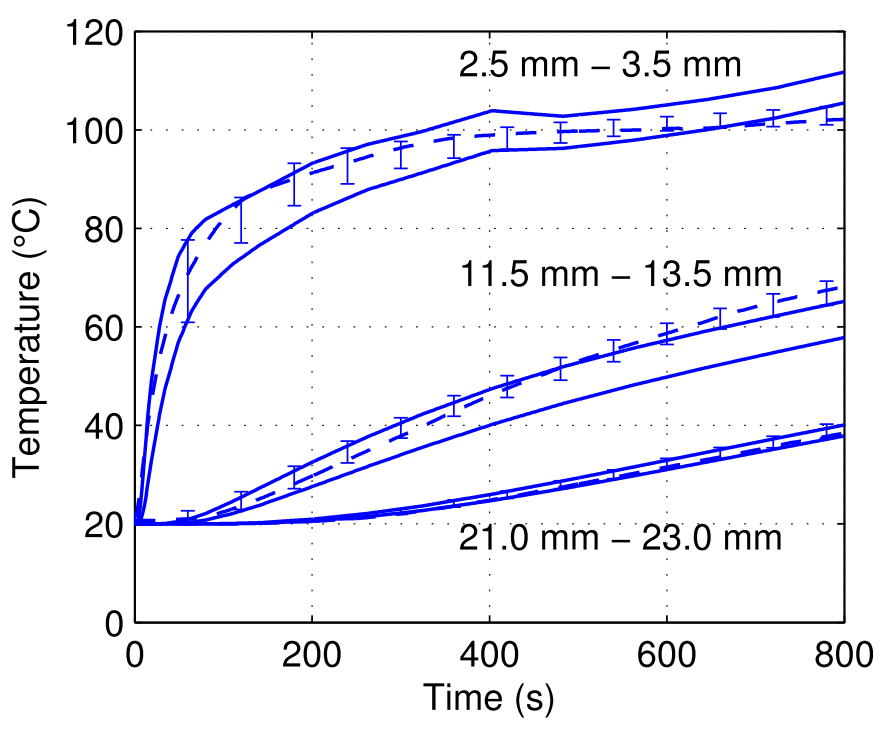

Fig. 5. Comparison of measured temperatures and simulated temperatures for the three zones of temperature measurement during cooking at $215^{\circ} \mathrm{C}$. Experimental data are represented by dashed lines (median value and first and last quartiles) and simulated data at the lower and higher limit of each zone are represented by solid lines.

the vaporisation of water exuding from the product $E_{\text {evap }}$ and (iv) the energy lost by the product due to heat exchange with its surroundings $E_{\text {loss. }}$.

The most obvious trend on this graph was that the higher the setpoint temperature, the more rapid was the rise in $E_{\text {tot }}$ and $E_{\text {evap }}$. In all tests, it was also interesting to note that throughout the heating process, a very large share of the energy received by the meat sample was consumed by the vaporisation of water exuding from it. Although this water arose initially from the lowest zone of the product, it was also continuously being transported from the central zone by means of an efficient mass diffusion mechanism within the porous structure of minced meat. During the tests performed at $128^{\circ} \mathrm{C}, 215^{\circ} \mathrm{C}$ and $255^{\circ} \mathrm{C}$, the total energy received by the product at the end of heating reached $58 \mathrm{~kJ}, 70 \mathrm{~kJ}$ and $85 \mathrm{~kJ}$ with $55 \%, 67 \%$ and $65 \%$ of this energy being consumed by the vaporisation of water from the product, respectively.
By contrast, the evolution of $E_{\text {sens }}$ appeared to be almost the same with the three temperatures. The only difference appeared at $255{ }^{\circ} \mathrm{C}$ when, after $500 \mathrm{~s}, E_{\text {sens }}$ increased more rapidly than at $128^{\circ} \mathrm{C}$ and 215 ${ }^{\circ} \mathrm{C}$. This difference reached $6000 \mathrm{~kJ}$ at the end of heating. It certainly resulted from an over-drying of the product's lower surface observed during this test at a high temperature, enabling a final increase in the temperature of this over-dried zone to more than $100{ }^{\circ} \mathrm{C}$.

When comparing the evolutions of $E_{\text {sens }}$ and $E_{\text {evap }}$, it was interesting to note that at the start of heating, and although the product started to dry immediately, $E_{\text {sens }}$ was always slightly higher that $E_{\text {evap }}$, with a negative correlation between the temperature set-point and $E_{\text {evap }}$ becoming higher than $E_{\text {sens }}\left(40 \mathrm{~s}, 80 \mathrm{~s}\right.$ and up to $400 \mathrm{~s}$ at $255^{\circ} \mathrm{C}, 215^{\circ} \mathrm{C}$ and $128{ }^{\circ} \mathrm{C}$, respectively).

It was also interesting to note that $E_{\text {loss }}$ represented a maximum of $4 \%$ of $E_{\text {tot }}$. This was attributed to the limited rise in product temperature at levels other than close to the heating device. Therefore, if the difference in temperature between the surrounding ambient air and the sample was small, so was the amount of energy lost.

To sum up, the calculations performed showed that during contact heating, a very large share of the heat received by the product was consumed by the vaporisation of liquid water exuding continuously from the product. This phenomenon was more pronounced when the heating surface temperature was high, and it also limited the rise in overall product temperature during contact heating. Only product zones close to the heating surface could be subjected to potential overdrying and thus had a temperature higher than $100{ }^{\circ} \mathrm{C}$. These results are in accordance with those obtained by Cernela et al. (2015) during the contact heating of solid model foods where the same conclusions were reached, but by only considering the kinetics of the rise in product temperature during heating.

\subsection{Lower surface temperature of the product and contact heat transfer coefficient}

As explained in section 3, validation of the model enabled the calculation of variations in the product's lower surface temperature $T_{F S}$ and the contact heat transfer coefficient $h_{c t}$ during these different experiments.

Fig. 7(a) shows the evolution of $T_{F S}$ during contact heating tests at $128^{\circ} \mathrm{C}, 215{ }^{\circ} \mathrm{C}$ and $255^{\circ} \mathrm{C}$. No general pattern of variation was noted a)

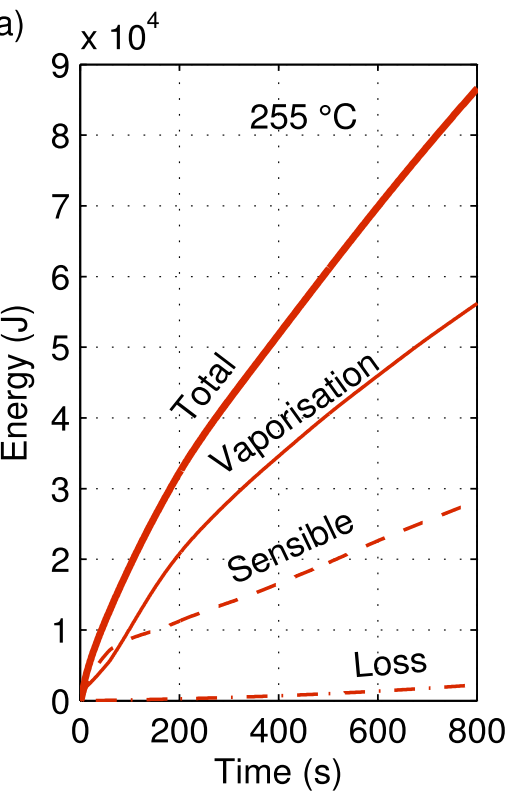

b)

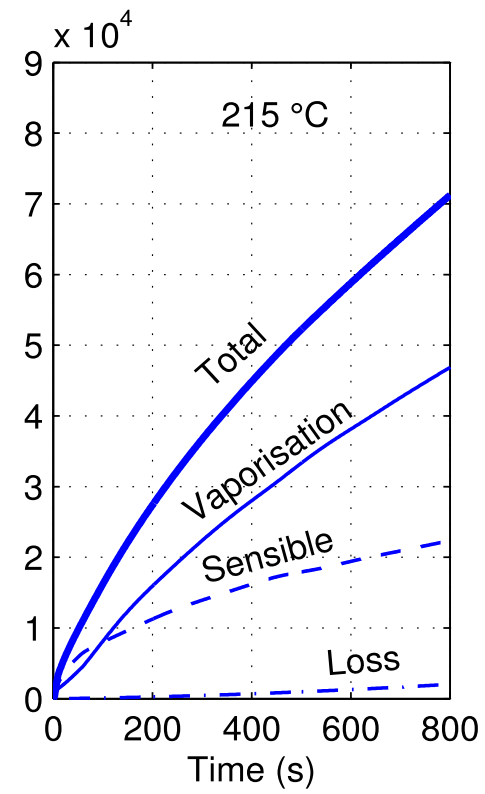

c)

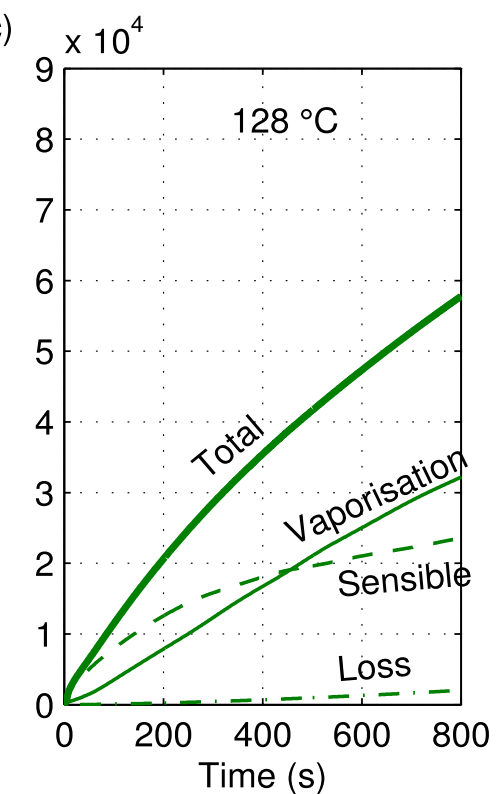

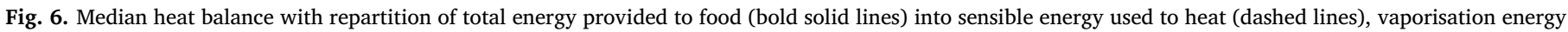
used to dry (solid lines) and lost energy (dot-dashed lines) at $255^{\circ} \mathrm{C}$ (a), $215^{\circ} \mathrm{C}$ (b) and $128^{\circ} \mathrm{C}$ (c). 

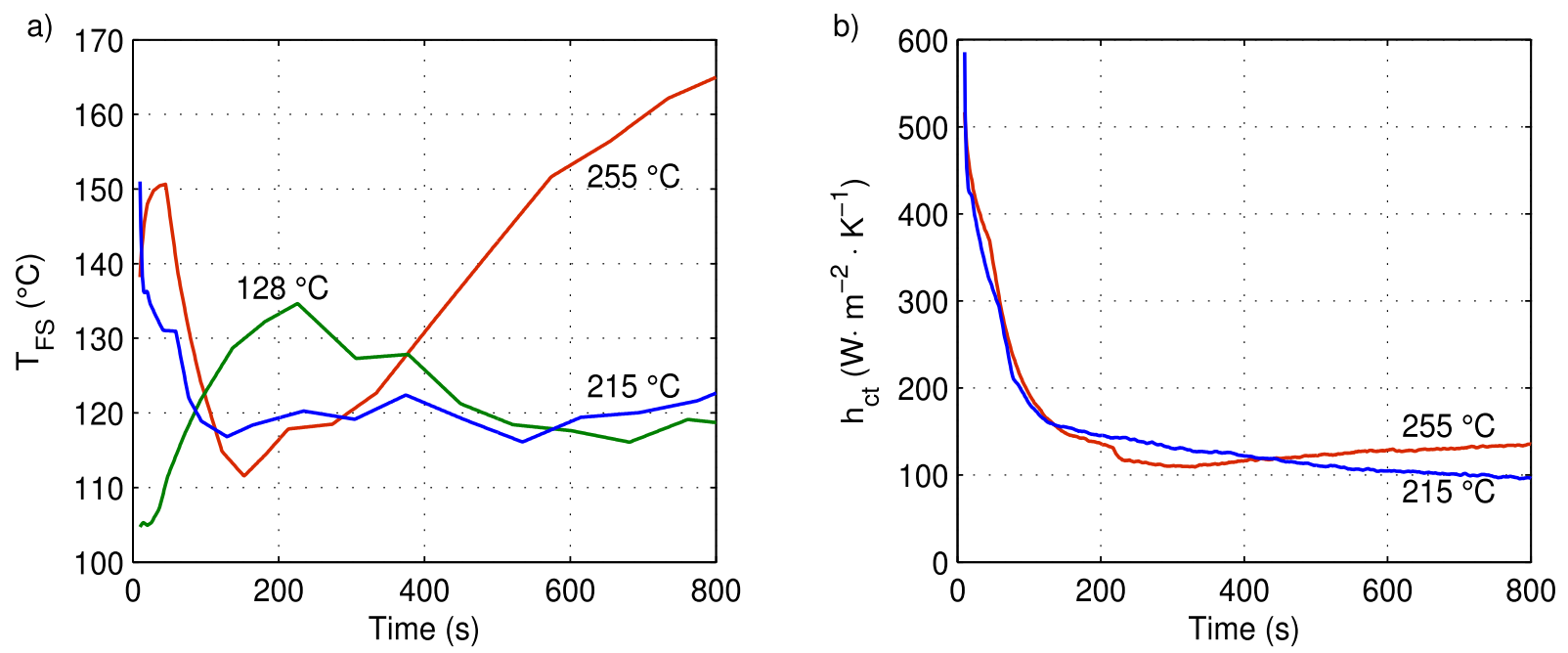

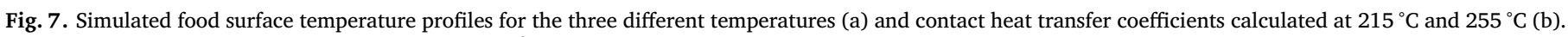
Average surface temperatures calculated by COMSOL ${ }^{\circ}$ software according to section 3.4.

concerning this variable. It could however be seen that after $10 \mathrm{~s}$ of heating, the temperature of the lower surface was always higher than $100{ }^{\circ} \mathrm{C}$. This confirmed the existence of a massive heat exchange between the product and the heating surface at the start of heating. For heating tests at $128{ }^{\circ} \mathrm{C}$ and $215^{\circ} \mathrm{C}$, the product's lower surface temperature varied between $110{ }^{\circ} \mathrm{C}$ and $130{ }^{\circ} \mathrm{C}$ whereas when heating at $255{ }^{\circ} \mathrm{C}$, this variable continued to rise steadily after $300 \mathrm{~s}$ of heating to reach a final value of $165{ }^{\circ} \mathrm{C}$. This last observation thus confirmed that during this test, drying of the product at this location became increasingly pronounced so that the temperature of this surface could rise at a significant rate.

To calculate the contact heat transfer coefficient, only the results at $215{ }^{\circ} \mathrm{C}$ and $255^{\circ} \mathrm{C}$ are shown in Fig. $7\left(\right.$ b) because at $128{ }^{\circ} \mathrm{C}$, the uncertainties regarding the temperature calculations of both the heating surface and product's lower surface made the difference between these two values too small to enable the calculation of $h_{c t}$ using equation (10). By contrast, the temperature difference between these two surfaces for tests at $215{ }^{\circ} \mathrm{C}$ (between $40{ }^{\circ} \mathrm{C}$ and $100{ }^{\circ} \mathrm{C}$ ) and at $255^{\circ} \mathrm{C}$ (between $70{ }^{\circ} \mathrm{C}$ and $140{ }^{\circ} \mathrm{C}$ ) confirmed that they were higher than the calculation uncertainties and thus enabled the calculation of $h_{c t}$ for all heating durations. It can be seen in Fig. 7(a) that despite the huge differences seen in the patterns of variation for the heating surface and product lower surface's temperatures (as shown in Figs. 4(b) and 7(a)), the calculated profiles of variation of $h_{c t}$ appeared to be very similar for the heating tests at $215{ }^{\circ} \mathrm{C}$ and $255{ }^{\circ} \mathrm{C}$. Therefore, at these temperature levels, the heating surface temperature did not appear to influence the contact heat transfer coefficient. Pan and Singh (2002) and Wichchukit et al. (2001) observed a decrease in the contact heat transfer coefficient when the heating surface temperature increased, but their result was obtained with a heating surface temperature below $200{ }^{\circ} \mathrm{C}$. During this study, the initial heat transfer coefficient value was $\approx 500 \mathrm{~W} \cdot \mathrm{m}^{-2} \cdot \mathrm{K}^{-1}$ and it fell rapidly after the start of heating to reach a nearly constant value of $100 \mathrm{~W} \cdot \mathrm{m}^{-2} \cdot \mathrm{K}^{-1}$. As heating progressed, the quality of the thermal contact between the product and surface tended to deteriorate markedly, probably due to the water exuding from the product and the consequent emission of vapour into the interstitial space between the two media. In addition, the formation of a crust at this location (visualised after the heating experiments) also contributed to impairing the quality of the physical and thermal contact between the heating surface and heated product. The $h_{c t}$ values falling from 500 to $100 \mathrm{~W} \cdot \mathrm{m}^{-2} \cdot \mathrm{K}^{-1}$ during the present study were of the same order of magnitude as those measured in previous studies on the single-faced grilling of minced meat (Houšová and Topinka, 1985; Pan and Singh, 2002). The results obtained by Houšová and Topinka (1985) on thawed meat showed a rapid increase in $h_{c t}$ at the start of heating, to reach values of between 175 and $230 \mathrm{~W} \cdot \mathrm{m}^{-2} \cdot \mathrm{K}^{-1}$, whereas Pan and Singh (2002) who were studying frozen meat saw a slower rise in $h_{c t}$ to reach a final value of $300 \mathrm{~W} \cdot \mathrm{m}^{-2} \cdot \mathrm{K}^{-1}$, a value that remained constant until the end of heating.

\section{Conclusion}

Contact heat transfer was experimentally studied in the particular case of grilling of minced turkey meat. To reach this aim, an original heating device was developed in order to achieve continuous and noninvasive measurement of (i) the contact heat flux between the heating surface and the heated product's lower surface and (ii) the temperature of the heating surface. The evaluation of these two variables was performed by solving an inverse heat transfer problem written on an Inconel cylinder inserted in the upper part of the heating device. In parallel, a simplified heat and mass transfer model was developed to predict local temperature rise and moisture loss kinetics inside the meat sample. This model, once validated on experimental temperatures inside the product, allowed us to calculate the continuous variations of the product's lower surface temperature. For all the heating tests, this temperature increased very rapidly above $100{ }^{\circ} \mathrm{C}$ confirming the existence of a massive heat exchange between the product and the heating surface at the start of heating. The drying of the product is hence very rapid at this location leading to the formation of a crust from the earlier stage of the heating.

The use of the product's lower surface temperature in combination with the experimental measurements of contact heat flux allowed us to calculate the continuous variations of the contact heat transfer coefficient. This coefficient quantifies the quality of the thermal contact between the two solids in contact, taking into account the effect of all the physicochemical phenomena occurring at the product's lower surface during heating (formation of a crust, release of cooking exudates). At $215{ }^{\circ} \mathrm{C}$ and $255^{\circ} \mathrm{C}$, this coefficient ranged from 500 at the start of the heating process down to $100 \mathrm{~W} \cdot \mathrm{m}^{-2} \cdot \mathrm{K}^{-1}$ at the end of it. This result highlights the fact that, for the experimental range covered in this study, the modification of the product's lower surface during contact heating tends to lower the quality of heat exchange with the heating surface.

Using the model developed here, it was also shown that the energy consumed by the vaporisation of the water exuding from the product during heating represented $55 \%, 67 \%$ and $65 \%$ of the total energy received by it during the tests at $128^{\circ} \mathrm{C}, 215{ }^{\circ} \mathrm{C}$ and $255{ }^{\circ} \mathrm{C}$, respectively. The results also suggested that the level of heating temperature had 
more effect on product moisture loss kinetics than on product temperature rise kinetics, this temperature rise being always limited by the vaporisation of water in the interstitial space between the product and the heating surface.

Overall, the experimental and theoretical results obtained in this study enabled us to have a better and more quantitative understanding of the process of contact heating. Using the heating device proposed here, further experimental studies must hence be conducted for a wide variety of solid or liquid food product. The results of these studies can guide us into selecting appropriate heating temperature in order to avoid the excessive heating and drying of the product's lower surface. A more complex modelling approach needs also to be carried out in order to predict the local values of product moisture content and be able to estimate the thickness of the crust formed at the product's lower surface and known to affect the sensory properties of the products heated by contact.

\section{Funding}

This research did not receive any specific grant from funding agencies in the public, commercial, or not-for-profit sectors.

\section{References}

Abraham, J., Sparrow, E., 2007. A thermal-ablation bioheat model including liquid-tovapor phase change, pressure- and necrosis-dependent perfusion, and moisture-dependent properties. Int. J. Heat Mass Tran. 50, 2537-2544. https://doi.org/10.1016/ j.ijheatmasstransfer.2006.11.045.

Boskou, G., Salta, F., Chiou, A., Troullidou, E., Andrikopoulos, N., 2006. Content of trans,trans-2,4-decadienal in deep-fried and pan-fried potatoes. Eur. J. Lipid Sci. Technol. 108, 109-115. https://doi.org/10.1002/ejlt.200500236\}.

Cernela, J., Heyd, B., Broyart, B., 2014. Evaluation of heating performances and associated variability of domestic cooking appliances (oven-baking and pan-frying). Appl. Therm. Eng. 62, 758-765. https://doi.org/10.1016/j.applthermaleng.2013.08.045\}.

Cernela, J., Heyd, B., Keller, S., Bailleul, J., Maillard, M., Bonazzi, C., Broyart, B., 2015. Experimental study of heat and mass transfer phenomena during the contact heating of solid food models. J. Food Eng. 146, 99-106. https://doi.org/10.1016/j.jfoodeng. 2014.09.007.

Clerjon, S., Kondjoyan, A., Bonny, J.M., Portanguen, S., Chevarin, C., Thomas, A., Bauchart, D., 2012. Oil uptake by beef during pan frying: impact on fatty acid composition. Meat Sci. 91, 79-87. https://doi.org/10.1016/j.meatsci.2011.12.009\}.

Erdoğdu, F., 2008. A review on simultaneous determination of thermal diffusivity and heat transfer coefficient. J. Food Eng. 86, 453-459. https://doi.org/10.1016/j. jfoodeng.2007.10.019.

Haak, L., Sioen, I., Raes, K., Van Camp, J., De Smet, S., 2007. Effect of pan-frying in different culinary fats on the fatty acid profile of pork. Food Chem. 102, 857-864. https://doi.org/10.1016/j.foodchem.2006.06.054.

Houšová, J., Topinka, P., 1985. Heat transfer during contact cooking of minced meat patties. J. Food Eng. 4, 169-188. https://doi.org/10.1016/0260-8774(85)90002-0.

Incropera, F.P., DeWitt, D.P., Bergman, T.L., Lavine, A.S., 2007. Fundamentals of Heat and Mass Transfer, sixth ed. John Wiley \& Sons, Hoboken, NJ.

Kalogeropoulos, N., Kotsiopoulou, C., Mylona, A., Christea, M., Andrikopoulos, N., 2006. Compositional changes and enrichment of mediterranean finfish during pan frying with virgin olive oil. Ecol. Food Nutr. 45, 171-188. https://doi.org/10.1080/ 03670240600648930\}.

Kondjoyan, A., Kohler, A., Realini, C.E., Portanguen, S., Kowalski, R., Clerjon, S., Gatellier, P., Chevolleau, S., Bonny, J.M., Debrauwer, L., 2014. Towards models for the prediction of beef meat quality during cooking. Meat Sci. 97, 323-331. https:// doi.org/10.1016/j.meatsci.2013.07.032.

Madhusudana, C., 1996. Thermal Contact Conductance, 1 ed. Springer-Verlag, New York. https://doi.org/10.1007/978-1-4612-3978-9.

Marcotte, M., Taherian, A.R., Karimi, Y., 2008. Thermophysical properties of processed meat and poultry products. J. Food Eng. 88, 315-322. https://doi.org/10.1016/j. jfoodeng.2008.02.016\}.

Özişik, M., Orlande, H., 2000. Inverse Heat Transfer. Fundamentals and Applications, 3 ed. Taylor \& Francis, New York 156032838X.

Pan, Z., Singh, R., 2002. Heating surface temperature and contact-heat transfer coefficient of a clam-shell grill. Lebensm. Wiss. Technol. 35, 348-354. https://doi.org/10.1006/ fstl.2001.0881\}.

Pan, Z., Singh, R., Rumsey, T., 2000. Predictive modeling of contact-heating process for cooking a hamburger patty. J. Food Eng. 46, 9-19. https://doi.org/10.1016/S02608774(00)00063-7\}.

Portanguen, S., Ikonic, P., Clerjon, S., Kondjoyan, A., 2014. Mechanisms of crust development at the surface of beef meat subjected to hot air: an experimental study. Food Bioprocess Technol. 7, 3308-3318. https://doi.org/10.1007/s11947-014-1321-y.

Rastogi, N.K., 2012. Recent trends and developments in infrared heating in food processing. Crit. Rev. Food Sci. Nutr. 52, 737-760. https://doi.org/10.1080/10408398. 2010.508138\}.

Sanz-Serrano, F., Sagues, C., Feyissa, A.H., Adler-Nissen, J., Llorente, S., 2017. Modeling of pancake frying with non-uniform heating source applied to domestic cookers. J. Food Eng. 195, 114-127. https://doi.org/10.1016/j.jfoodeng.2016.09.027\}.

Sioen, I., Haak, L., Raes, K., Hermans, C., De Henauw, S., De Smet, S., Van Camp, J., 2006. Effects of pan-frying in margarine and olive oil on the fatty acid composition of cod and salmon. Food Chem. 98, 609-617. https://doi.org/10.1016/j.foodchem.2005.06. 026\}.

Taine, J., Petit, J.P., 1998. Transferts thermiques Mécanique des fluides anisothermes. Dunod, Paris.

Vanin, F., Michon, C., Lucas, T., 2013. Effect of the drying rate on the complex viscosity of wheat flour dough transforming into crust and crumb during baking. J. Cereal. Sci. 58, 290-297. https://doi.org/10.1016/j.jcs.2013.06.003.

Wichchukit, S., Zorrilla, S., Singh, R., 2001. Contact heat transfer coefficient during double-sided cooking of hamburger patties. J. Food Process. Preserv. 25, 207-221. https://doi.org/10.1111/j.1745-4549.2001.tb00455.x\}. 